\title{
Fossil eggshell cuticle elucidates dinosaur nesting ecology
}

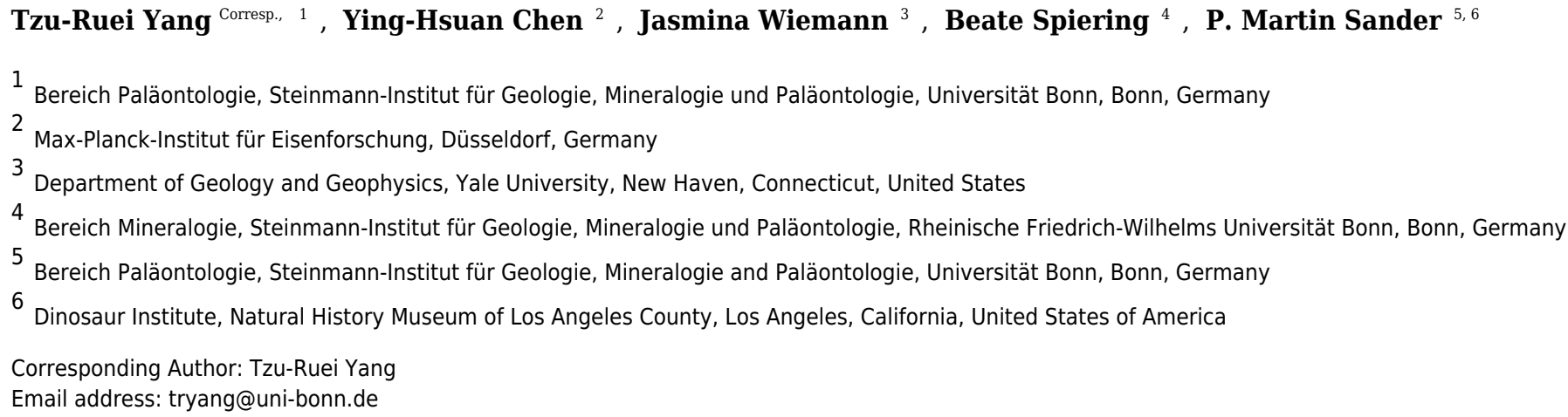

The cuticle layer consisting mainly of lipids and hydroxyapatite (HAp) atop the mineralized avian eggshell is a protective structure that prevents the egg from dehydration and microbial invasions. Previous ornithological studies have revealed that the cuticle layer is also involved in modulating the reflectance of eggshells in addition to pigments (protoporphyrin and biliverdin). Thus, the cuticle layer represents a crucial trait that delivers ecological signals. While present in most modern birds, direct evidence for cuticle preservation in stem birds and non-avian dinosaurs is yet missing. Here we present the first direct and chemical evidence for the preservation of the cuticle layer on dinosaur eggshells. We analyze several theropod eggshells from various localities, including oviraptorid Macroolithus yaotunensis eggshells from the Late Cretaceous deposits of Henan, Jiangxi, and Guangdong in China and alvarezsaurid Triprismatoolithus eggshell from the Two Medicine Formation of Montana, United States, with the scanning electron microscope (SEM), electron probe micro-analysis (EPMA), and Raman spectroscopy (RS). The elemental analysis with EPMA shows high concentration of phosphorus at the boundary between the eggshell and sediment, representing the hydroxyapatitic cuticle layer (HAp). Depletion of phosphorus in sediment excludes the allochthonous origin of the phosphorus in these eggshells. The chemometric analysis of Raman spectra collected from fossil and extant eggs provides further supportive evidence for the cuticle preservation in oviraptorid and probable alvarezsaurid eggshells. In accordance with our previous discovery of pigments preserved in Cretaceous oviraptorid dinosaur eggshells, we validate the cuticle preservation on dinosaur eggshells through deep time and offer a yet unexplored resource for chemical studies targeting the evolution of dinosaur nesting ecology. Our study also suggests that the cuticle structure can be traced far back to maniraptoran dinosaurs and enhance their reproductive success in a warm and mesic 
habitat such as Montana and southern China during the Late Cretaceous. 


\section{Fossil eggshell cuticle elucidates dinosaur nesting ecology}

2

3 4

5

6

7 2Max-Planck-Institut für Eisenforschung, Max-Planck-Straße 1, 40237 Düsseldorf, Germany

$8 \quad{ }^{3}$ Department of Geology and Geophysics, Yale University, 06511 New Haven, CT, U.S.A.

9 Bereich Mineralogie, Steinmann-Institut für Geologie, Mineralogie und Paläontologie,

10 Universität Bonn, Poppelsdorfer Schloss, 53115 Bonn, Germany

11 Dinosaur Institute, Natural History Museum of Los Angeles County, 900 Exposition Boulevard, 12 Los Angeles, CA 90007, USA

13

14 Corresponding author:

15 Tzu-Ruei Yang ${ }^{1}$

16

17 Email address: tryang@uni-bonn.de or lereage@gmail.com 


\begin{abstract}
18 Abstract
19 The cuticle layer consisting mainly of lipids and hydroxyapatite (HAp) atop the mineralized

20 avian eggshell is a protective structure that prevents the egg from dehydration and microbial

21 invasions. Previous ornithological studies have revealed that the cuticle layer is also involved in

22 modulating the reflectance of eggshells in addition to pigments (protoporphyrin and biliverdin).

23 Thus, the cuticle layer represents a crucial trait that delivers ecological signals. While present in

24 most modern birds, direct evidence for cuticle preservation in stem birds and non-avian

25 dinosaurs is yet missing. Here we present the first direct and chemical evidence for the

26 preservation of the cuticle layer on dinosaur eggshells. We analyze several theropod eggshells

27 from various localities, including oviraptorid Macroolithus yaotunensis eggshells from the Late

28 Cretaceous deposits of Henan, Jiangxi, and Guangdong in China and alvarezsaurid

29 Triprismatoolithus eggshell from the Two Medicine Formation of Montana, United States, with

30 the scanning electron microscope (SEM), electron probe micro-analysis (EPMA), and Raman

31 spectroscopy (RS). The elemental analysis with EPMA shows high concentration of phosphorus at the boundary between the eggshell and sediment, representing the hydroxyapatitic cuticle layer (HAp). Depletion of phosphorus in sediment excludes the allochthonous origin of the phosphorus in these eggshells. The chemometric analysis of Raman spectra collected from fossil and extant eggs provides further supportive evidence for the cuticle preservation in oviraptorid and probable alvarezsaurid eggshells. In accordance with our previous discovery of pigments preserved in Cretaceous oviraptorid dinosaur eggshells, we validate the cuticle preservation on dinosaur eggshells through deep time and offer a yet unexplored resource for chemical studies targeting the evolution of dinosaur nesting ecology. Our study also suggests that the cuticle structure can be traced far back to maniraptoran dinosaurs and enhance their reproductive 41 success in a warm and mesic habitat such as Montana and southern China during the Late 42 Cretaceous.
\end{abstract}


43

44

45

46

47

48

49

50

51

52

53

54

55

56

57

58

59

60

61

62

63

64

65

66

67

68

69

70

71

72

73

74

75

76

77

78

79

80

81

82

83

84

85

86

87

88

\section{Introduction}

Cuticle structures and functions

An avian egg is an evolutionary invention that protects the developing embryo against mechanical damage, dehydration, and microbial invasion (Romanoff \& Romanoff, 1949; Board \& Fuller, 1974). This multi-functionality is contributed to by both mineralized and nonmineralized organic layers, which exhibit unique biomaterial properties. The avian eggshell forms inside the uterus. The final layer to be deposited, the eggshell cuticle, represents the interface between the embryo inside and its outside environment. Many bird eggs are equipped with a cuticle layer; however, this structure is absent in some clades such as parrots, petrels, and pigeons (D'Alba et al., 2016). The cuticle layer is often described as "waxy" due to its high amount of lipids, which keep the internal fluids from evaporating and therefore protect the encased embryo from desiccation. In addition to lipids, the avian cuticle contains proteins, polysaccharides, calcium carbonate (vaterite), calcium phosphates (hydroxyapatite, HAp), and pigments (Wedral et al., 1974; Nys et al., 1991; Packard \& DeMarco, 1991; Dennis et al., 1996; Mikhailov \& Ornithologists' Club, 1997; Fraser, Bain \& Solomon, 1999; Cusack, Fraser \& Stachel, 2003; Igic et al., 2015).

The cuticle layer varies in thickness (up to $12 \mu \mathrm{m}$ ) and has a patchy distribution on the eggshell (Board \& Halls, 1973). Basically, the cuticle is divided into two distinct layers, including an amorphous HAp/vaterite inner layer and a proteinaceous outer layer (Simons, 1971; Dennis et al., 1996; Fraser, Bain \& Solomon, 1999). The inner cuticle layer is composed of needle-like HAp/vaterite crystals on some avian eggs but present in the form of nanospherical HAp/vaterite on other avian eggs (Dennis et al., 1996; D’Alba et al., 2014). A recent study suggested that the circular mineral nanospheres on eggshells serve an antimicrobial function for species nesting in humid environment (D’Alba et al., 2016). D'Alba et al. (2016) also proposed that eggs in humid environments tend to have more cuticular nanospheres to prevent flooding and microbial invasions. Conversely, in arid environments, lacking a cuticle layer would be beneficial for embryos in eggs with low conductance, as Deeming (1987) suggested. However, in an extreme environment such as the Antarctic, Adélie penguin eggs have a thick cuticle layer to reduce water loss (Thompson \& Goldie, 1990). Besides, the intactness of the cuticle is an indicator for the freshness of an egg (Rodríguez-Navarro et al., 2013). Several studies suggested that the cuticle functions as a lubricant that facilitates egg rotation in the uterus (Rahman et al., 2009). Moreover, a recent study shows that the cuticle also modulates ultraviolet reflectance of avian eggshells (Fecheyr-Lippens et al., 2015). For instance, an extremely smooth cuticle produces glossiness and iridescence in tinamou eggs (Igic et al., 2015).

The cuticle is commonly observed on most calcified eggshells, but it shows different structures and characteristics between reptilian and avian eggshells (Ferguson, 1982). The cuticle on reptilian eggshells is no longer present after two weeks of laying (Ferguson, 1982); hence, the author concluded that the reptilian cuticle is not equivalent to the cuticle present on avian eggshells. Ferguson (1982) hypothesized that a true cuticle layer is not present on alligator eggshell. Conversely, avian eggshells exhibit an inner cuticle layer composed of HAp/vaterite granules or amorphous needle-like HAp/vaterite crystals, which are absent on reptilian eggshells. Several studies on extant eggshell have identified cuticle presence by means of the scanning electron microscopy (SEM) and transmission electron microscopy (TEM) (Fink et al., 1993; Fraser, Bain \& Solomon, 1999). Kusada et al. (2011) used energy dispersive X-ray analysis (EDX) to map the phosphorus (P) and calcium (Ca) distribution in several extant avian eggshells and discovered that $\mathrm{P}$ is confined to the cuticle layer. Although the $\mathrm{P}$ concentration in the cuticle 
89 varies greatly between different bird species, $\mathrm{P}$ is a distinct marker for identifying the cuticle

90 layer in case of $\mathrm{P}$ depletion in sediment. Although it is still not clear how $\mathrm{P}$ functions during the

91 eggshell formation, a study suggested that the inclusion of $\mathrm{P}$ in the biomineral terminates

92 eggshell growth since it competes with calcium during the eggshell crystallization (Cusack,

93 Fraser \& Stachel, 2003).

94

\section{Discoveries of fossilized organic membranes}

Since the cuticle is composed of proteins, polysaccharides, lipids, calcium carbonate, calcium phosphates, and pigments, it is seemingly unlikely to preserve during the fossilization process. A previous report concerning spherical (Oölithus spheroides) and elongated (Oölithus elongatus) eggs from Laiyang, Shandong, China, suggested that the cuticle is preserved in elongated eggs but not in spherical ones (Chow, 1954). Another similar report on ornithoid eggshells from Naran-Bulak, Mongolia also described possible cuticle preservations (Sochava, 1971), but no diagnostic chemical data were obtained. Kohring \& Hirsch (1996) studied the crocodilian and ornithoid eggshells from the middle Eocene of the Geiseltal, Germany, and suggested possible cuticle and shell membrane preservation. Later, with the SEM, several studies on dinosaur eggshells, Cretaceous bird eggshells, and fossil moa eggshells showed the potential of cuticle preservation (Mikhailov, 1991; Varricchio \& Jackson, 2004; Jackson \& Varricchio, 2010; Oskam et al., 2010). Although these studies provided a new avenue to understanding softpart preservation, all previous studies described possible cuticle preservation only based on micro-structural comparisons with the cuticle of extant avian eggshells. Jackson and Varricchio (2010) described a new ootaxon - Triprismatoolithus stephensi - of probable alvarezsaurid affinities. These authors reported a cracked and amorphous surface overlying the external layer and suggested it might be a layer of cuticle. Nevertheless, they did not further investigate the possible cuticle layer by means of any other analyses. Therefore, all previous reports regarding the cuticle preservation were constrained to micro-morphological observations. The only chemical evidence supporting the fossilization potential of cuticle through deep time is offered by a study on oviraptorid eggshells focusing on the two main eggshell pigments, biliverdin and protoporphyrin (Wiemann et al., 2017). The protoporphyrin is deposited predominantly in the cuticle layer (Schwartz et al., 1975; Nys et al., 1991; Mikšík et al., 2007; Nys \& Guyot, 2011), thus providing indirect evidence of cuticle preservation in the preservation of endogenous protoporphyrin (Wiemann et al., 2017). Although Wilson et al. (2017) demonstrated that there is no codependence of the deposition of pigment and cuticle, the preserved pigments in the oviraptorid eggshell could derive from the eggshell or the preserved cuticle layer and in the latter instance would be indicative of cuticle preservation. We hence posited that the cuticle was completely, or partially, preserved on the oviraptorid eggshells. In addition to the cuticle layer, the membrana testacea (eggshell membranes), a proteinaceous meshwork that underlies the mineralized eggshell and separates egg yolk and eggshell, is also a crucial membrane. Unlike the cuticle layer, the preservation of membrana testacea has been reported from titanosaurid and Lufengosaurus eggs (Grellet-Tinner et al., 2005; Reisz et al., 2013), yet never in theropod eggs.

\section{Nesting ecology of dinosaurs and modern birds}

Dinosaur nesting ecology is a long-standing and intriguing research topic. Among all dinosaurs, the nesting type of titanosaur, troodontid, and oviraptorid dinosaurs are comparatively well documented (Jackson et al., 2007; Varricchio et al., 2013; Wiemann et al., 2017). These dinosaurs adopted different nesting strategies in their clutch arrangement, nest architecture, and 
135 nesting mode. Deeming (2006) and Tanaka, Zelenitsky \& Therrien (2015) roughly categorized

136 two nesting modes in dinosaurs, including open and buried nesting modes. Most birds build open

137 nests, while the buried nesting mode is only observed in megapode birds. In a wet incubation

138 environment such as a buried megapode nest, eggs are exposed to a higher risk of asphyxiation

139 and microbial infection (Board \& Fuller, 1974; Board, 1982; D'Alba et al., 2017). D'Alba et al.

140 (2016) provided the first report regarding the association between the cuticular nanospheres and

141 nesting modes. These authors discovered that the birds nesting in more mesic environments tend

142 to lay eggs yielding cuticular nanospheres. The nanospheres in the cuticle layer, therefore,

143 represents a structural adaptation that prevents eggs from microbial invasions (D'Alba et al.,

144 2016). However, eggs of Adélie penguins are also encapsulated by a thick cuticle layer that

145 prevents eggs from water loss in the severe cold Antarctic environment (Thompson \& Goldie,

146 1990). These lines of evidence suggest that the cuticle layer is an evolutionarily labile structure

147 and thus varies greatly in accordance with the nesting environment. D'Alba et al. (2016) further

148 suggested that cuticular nanospheres are an ancestral trait; however, this trait has been lost

149 multiple times and is absent in some avian clades.

150 In dinosaurs, it was suggested that titanosaurs also employed the buried nesting mode

151 (Sander et al., 1998; Grellet-Tinner \& Fiorelli, 2010; Sander et al., 2008; Vila et al., 2010;

152 Hechenleitner, Grellet-Tinner \& Fiorelli, 2015). The low porosity of titanosaur eggs from Auca

153 Mahuevo, however, suggested that the titanosaurs from Auca Mahuevo did not bury their eggs

154 (Jackson, 2007; Sander et al., 2008). The Auca Mahuevo exception demonstrates that the

155 eggshell is a labile structure, which alters according to the environment. In comparison with the

156 well-documented titanosaur nesting ecology, the nesting ecology of theropods has remained

157 uncertain until recent times. A nesting Nemegtomaia discovered in Mongolia indicated a semi-

158 open nesting mode based on sedimentological evidence (Fanti, Currie \& Demchig, 2012). The

159 discovery of pigmentation in oviraptorid eggshells strongly suggested that the oviraptorid eggs

160 were laid in an at least partially open nest (Wiemann et al., 2017). Yang et al. (2015, see also

161 Wiemann et al., 2017) further supported the semi-open nesting mode according to the

162 heterogeneous distribution of porosity in an oviraptorid egg and taphonomic evidence. While

163 there is no evidence of pigmentation in troodontid eggshells because these have not been

164 analyzed chemically so far, the heterogeneous distribution of porosity suggests that the

165 troodontid dinosaurs might also have laid their eggs in a semi-open nest (Varricchio et al., 1997;

166 Varricchio et al., 2013).

167 The goal of this study is to present further evidence of cuticle preservation on dinosaur

168 eggshells by means of SEM imaging, elemental analysis, and RS. In particular, we analyzed

169 theropod eggshells from the Nanxiong Group in China and the Two Medicine Formation in

170 Montana, USA. Both the Nanxiong Group and Two Medicine Formation represent fluvial

171 deposits, indicating a probable humid climate in both areas during the Late Cretaceous. In

172 addition, nesting on the ground or in a mound in a wet environment increases the risk of

173 microbial invasions (D'Alba et al., 2016), a cuticle layer should thus be prevalent on eggshells of

174 ground nesting theropods in a humid climate.

175

176

177

178

179

180

\section{Material and methods}

\section{Materials}

In order to standardize our following analyses, domestic chicken eggshell (Gallus gallus domesticus) was obtained from a commercial source (supermarket). Two extant crocodilian eggshells (Crocodylus porosus and Tomistoma schlegelii) were sampled from the collection of 
181 the NMNS as negative controls (Table 1). The fossil materials include oviraptorid and probable 182 alvarezsaurid dinosaur eggshells (Table 1).

183 We studied three oviraptorid eggshell specimens that were collected from the Late

184 Cretaceous Nanxiong Group of three localities in China (Henan Province, Jiangxi Province, and

185 Guangdong Province) and are housed at the NMNS and STIPB. Based on eggshell

186 microstructure, all specimens were assignable to Macroolithus yaotunensis, which was laid by

187 the oviraptorid Heyuannia huangi (Cheng et al., 2008). Macroolithus yaotunensis is

188 characterized by an undulating boundary between two crystalline layers, i.e., the outer prismatic

189 layer and the inner mammillary layer (Supplemental Information; Zhao, 1975). The first

190 Macroolithus yaotunensis eggshell was taken from specimen NMNS CYN-2004-DINO-05-I,

191 which was collected from the Late Cretaceous Tangbian Formation of the Hongcheng Basin in

192 Jiangxi Province, China (Table 1). The Tangbian Formation is characterized by fine-grained

193 brownish-reddish sediments with dispersed coarse clasts and conglomerates, representing a

194 fluvial/alluvial environment with occasional stream flooding during the Campanian stage (Chen

195 et al., 2017). The second Macroolithus yaotunensis sample was collected as isolated shell

196 fragments from the Late Cretaceous Hugang Formation in the Liguanqiao Basin near Nanyang,

197 southwestern Henan Province, China (Table 1). This sample has been housed in STIPB since

1981985 and was described in Erben (1995). The Hugang Formation is composed of dark grayish

199 red breccia with interbeds of calcareous sandstone, indicating a fluvial/alluvial environment

200 (Zhang, 2009). The third Macroolithus yaotunensis sample was also obtained as isolated shell

201 fragments from the Late Cretaceous fluvial deposits of the Pingling Section of the Shanghu

202 Formation in the Nanxiong Basin, located in the northwestern part of Guangdong Province,

203 China (Table 1). The NE-SW striking Nanxiong Basin, which is filled with dark purplish silty

204 mudstone with interbeds of conglomerate, has produced numerous theropod egg clutches and

205 eggshell fragments (Erben, 1995).

206

207

208

209

210

211

212

213

214

215

216

217

218

219

220

221

222

223

224

225

226

The Triprismatoolithus stephensi eggshells (MOR ES101), probably attributable to alvarezsaurids (Agnolin et al., 2012; Varricchio \& Jackson, 2016), were collected as isolated shell fragments in the lower portion of the Two Medicine Formation in the Sevenmile Hill outcrops, Teton County, Montana, USA (Table 1). The Triprismatoolithus stephensi eggshell has three crystalline layers, including an external layer, prismatic layer, and mammillary layer, from outermost to innermost (Varricchio \& Jackson, 2016). The Two Medicine Formation is mostly composed of sandstone, deposited by rivers and deltas on the western shoreline of the Late Cretaceous Interior Seaway.

\section{Chemical analyses}

For the chemical analyses, we first used a VEGA TS5130 LM (Tescan) SEM at the STIPB to locate and image plausible cuticle preservation on the studied eggshells. The eggshells were naturally broken fragments and coated with gold for SEM observation. The operating conditions for the SEM were set as $20 \mathrm{kV}$ accelerating voltage.

All samples were cleaned with ethanol before chemical analyses. We then performed elemental analyses using the EPMA equipped with a WDS at the Section of Mineralogy of the STIPB to elucidate the P distribution in the radial section of dinosaur eggshells. All samples were polished, fixed on a glass slide with araldite histological resin, and then coated with carbon for the elemental analysis with EPMA. The elemental analyses were performed with a JEOL SUPERPROBE 8900 EPMA at the same lab. The operating conditions for the EPMA were set as $1 \mu \mathrm{m}$ beam diameter, $15 \mathrm{kV}$ accelerating voltage, and $15 \mathrm{nA}$ specimen current. The ZAF 
227

228

229

230

231

232

233

234

235

236

237

238

239

240

241

242

243

244

245

246

247

248

249

250

251

252

253

254

255

256

257

258

259

260

261

262

263

264

265

266

267

268

269

270

271

272

correction scheme was used. Natural and synthetic minerals were used as standards.

We performed two rounds of RS using two Raman spectrometers at the MPIE. For the first round, Raman Analysis I (referred to as RI hereafter)), we analyzed the domestic chicken eggshell from a commercial source with a WITec Alpha300 system with $532 \mathrm{~nm}$ wavelength laser light and a confocal 50x objective, each for 20 seconds. Since the cuticle on the chicken eggshell was easily identified with the naked eye, as well as under the SEM (Figs. 1C \& 1D), the first round confirmed the detectability by Raman spectroscopy of the HAp of the cuticle layer (Figs. 1E-F). Due to the incomplete preservation of the cuticle in the chicken eggshell, we performed Raman surface mapping on the area where we found possible cuticle remains using the SEM and EPMA previously.

Raman analysis II (referred to as RII hereafter) was performed using the Horiba Jobin Yvon GmbH LabRam Raman spectrometer equipped with a $632 \mathrm{~nm}$ laser. All results were obtained using the 10x objective of the integrated Olympus microscope. While the 10x objective is not strongly sensitive to rare compounds, it provides a larger field of view for faster qualitative detection of HAp on eggshell sample than in RI. In order to distinguish HAp and calcite from sediments, we collected Raman spectra of the fresh chicken eggshell, the studied fossil eggshells and their associated sediments (Fig. 2A). All Raman spectra of eggshells and their associated sediments during RII were imported into the statistics software $\mathrm{R}$ and normalized with the $\mathrm{R}$ package "ChemoSpec" (Hanson, 2017). We performed principle component analysis (PCA) on the spectral area of 500 to $1500 \mathrm{~cm}^{-1}$ using the same package (Fig. 2B).

\section{Results}

The cuticle layer on the Gallus eggshell was easily observed with the naked eye. The RI Raman spectrum from the Gallus eggshell shows a significant peak at $1087 \mathrm{~cm}^{-1}$ that arises from the calcite, which is the major component of eggshell (Fig. 1F). Another intense peak at $967 \mathrm{~cm}^{-1}$ was assigned to the $v_{3}$ symmetric stretching vibrations (Walters et al., 1990; Gergely et al., 2010; Frost et al., 2014; Igic et al., 2015). Targeting the $967 \mathrm{~cm}^{-1}$ peak, the Raman surface scan shows the patchy distribution of the HAp layer overlying the calcitic eggshell (Fig. 1E). The result demonstrates detectability of the inner HAp layer of the cuticle by RS.

On the outside of Macroolithus yaotunensis and Triprismatoolithus stephensi eggshell fragments, we also found peaks in these spectral regions (Fig. 2A). RII showed two intense broad peaks that are located between $1063-1097 \mathrm{~cm}^{-1}$ and $972-986 \mathrm{~cm}^{-1}$ in the spectra. The spectral range of 1063-1097 $\mathrm{cm}^{-1}$ can be assigned to the $\mathrm{C}-\mathrm{O}$ bond of calcite, which is observable in the spectra from all eggshells. The $972-986 \mathrm{~cm}^{-1}$ spectral ranges arose possibly from the phosphate ( $\mathrm{PO}_{4}^{3-}$ ) or hydrogen phosphate $\left(\mathrm{HPO}_{4}^{2-}\right.$ ) (Sauer et al., 1994; Crane et al., 2006; Igic et al., 2015). Importantly, the $972-986 \mathrm{~cm}^{-1}$ spectral ranges are present in the spectra from the chicken and dinosaur eggshells but absent in the ones from the crocodilian eggshells and surrounding sediments. The chemometric analysis using ChemoSpec suggests that both chicken and dinosaur eggshells show similar spectral pattern between $800 \mathrm{~cm}^{-1}$ and $1200 \mathrm{~cm}^{-1}$ (Fig. 2B). In addition, the spectra from the crocodilian eggshells and surrounding sediments occupy different chemospaces from the ones of dinosaur and chicken eggshells (Fig. 2B).

Under the polarizing microscope, the Macroolithus eggshell from the Hongcheng Basin of Jiangxi, China, displayed distinct two crystalline layers overlain by an enigmatic layer and surrounding sediment (Fig. 3A). These features are also present in the other two Macroolithus eggshells (see Supplemental Information). The uneven thickness of the prismatic layer in the Jiangxi Macroolithus eggshells was a result of unpolished natural fracture surface of the section 
273 (Fig. 3B). A possible patchy and flake-like cuticle layer was observed with SEM on the outer 274 surface of the Macroolithus and Triprismatoolithus eggshells (Figs. 3C \& 4B). Furthermore, an

275 enigmatic protruding fiber-like structure was recognized in the Triprismatoolithus eggshell (Figs.

276

277

278

279

280

281

282

283

284

285

286

287

288

289

290

291

292

293

294

295

296

297

298

299

300

301

302

303

304

305

306

307

308

309

310

311

312

313

314

315

316

317

318 4C-D). The diameter of the fiber-like structure is approximately $3 \mu \mathrm{m}$.

We performed ten elemental line-mappings on each eggshell with EPMA and targeted phosphorus of the HAp. Of the of total 30 line mappings on the three Macroolithus yaotunensis eggshell, only two of them, which were from the Jiangxi and Guangdong specimens, show a significant phosphorus peak on the boundary between the eggshell and surrounding sediment (Figs. 3D \& 3F). The elemental analysis also indicates the scarcity of the phosphorus in the surrounding sediment. In addition, the P concentration increases from the mammillary layer to the prismatic layer in all analyzed oviraptorid eggshells (Figs. 3D-F and raw data in the Supplemental Information).

In the EPMA line-scan on the Triprismatoolithus stephensi eggshell, three significant peaks for $\mathrm{P}$ were observed (Fig. 4E). The peak on the boundary between the eggshell and surrounding sediment indicates possible cuticle preservation (Fig. 4E). However, the other two peaks were seen in the sediment and on the boundary between the external layer and prismatic layer. The variation of $\mathrm{P}$ concentration between different eggshell layers was also observed in Triprismatoolithus stephensi eggshell (Fig. 4E and Supplemental Information). Although the P concentration within the mammillary and prismatic layers shows little variation, the external layer has a significantly lower concentration of $\mathrm{P}$ than the mammillary and prismatic layers (Fig. $4 \mathrm{E} \&$ raw data in the Supplemental Information).

\section{Discussion}

\section{Elemental analysis of theropod eggshells}

While previous studies have reported possible preservation of cuticle and membrana testacea (Chow, 1954; Kohring \& Hirsch, 1996; Grellet-Tinner, 2005; Jackson \& Varricchio, 2010; Reisz et al., 2013; Yang et al., 2015), none of these studies employed chemical analyses to test this hypothesis. In this study, elemental analysis suggests the preservation of the inner hydroxyapatitic cuticle layer based on the high concentration of $P$ at the boundary between eggshell and sediment. However, the peak that corresponds to a high concentration of $\mathrm{P}$ is not always present in each elemental line-scan. For instance, on the M. yaotunensis eggshell sample from the Liguangqiao Basin (Fig. 3E), a probable P-rich zone, instead of an abrupt peak, is shown near the boundary between the eggshell and surrounding sediment. RS analysis indeed revealed the existence of phosphates. Since RS scans a larger area than EPMA does, we suggest that the absence of an abrupt peak for a P-rich zone in those 28 line-scans is a result of incomplete preservation of the cuticle layer or a sampling bias during the EPMA analyses. The elemental analysis also shows that $\mathrm{P}$ is rare in the surrounding sediment from both the Nanxiong Group of China and the Two Medicine Formation of Montana, United States. The deficiency of

$\mathrm{P}$ in the sediment thus argues against an allochthonous origin of the $\mathrm{P}$ in the outermost part of the eggshell (Figs. 3D-F \& 4E). The chemometric comparison of the spectra derived from sediments also suggests the depletion of phosphate minerals in the sediments. Therefore, the peak in the sediment surrounding the Triprismatoolithus stephensi eggshell might be derived from the eggshell specimen itself.

The enigmatic fiber-like structure near the base of the mammillary layer in the Triprismatoolithus eggshell (Fig. 4D) may be a capillary vessel of the chorioallantoic membrane or a fiber of the membrana testacea. The elemental analyses cannot provide evidence for the 
319 preservation of the capillary vessels of the chorioallantoic membrane. SEM images show that the

320

321

322

323

324

325

326

327

328

329

330

331

332

333

334

335

336

337

338

339

340

341

342

343

344

345

346

347

348

349

350

351

352

353

354

355

356

357

358

359

360

361

362

363

364

vessels in the chorioallantoic membrane of modern chicken eggshells range in size from 3 to 10 $\mu \mathrm{m}$ (Maiber et al., 2016), similar to the fiber-like structure we observed in the Triprismatoolithus eggshell (Fig. 4D). However, the fiber-like structure in the Triprismatoolithus eggshell does not appear to be hollow, unlike a blood vessel (Schweitzer et al., 2005). It is therefore possible that the enigmatic fiber-like structure in the Triprismatoolithus eggshell represents a part of fossilized membrana testacea, which has never been described in theropod dinosaurs. The membrana testacea fibers in a chicken egg occasionally penetrate through the mammillary base (Ahmed, Suso \& Hincke, 2017) and are of the same size of around $3 \mu \mathrm{m}$ as the fiber-like structure we observed in the Triprismatoolithus egg (Fig. 4D). However, the hypothesis of fossilized membrana testacea requires more supporting evidence.

\section{Variation of $P$ concentration in eggshells}

Despite numerous studies on element distribution in modern avian and reptilian eggshells, dinosaur eggshells were rarely investigated from a chemical perspective. Several studies posited that $\mathrm{P}$ is a critical element that regulates eggshell growth (Fink et al., 1993; Dennis et al., 1996; Fraser, Bain \& Solomon, 1999; Cusack, Fraser \& Stachel, 2003). In Gallus gallus domesticus eggshells, a pattern of increasing P concentration from the mammillary layer to the prismatic layer has been reported (Cusack, Fraser \& Stachel, 2003). This pattern is similar to what we observed in oviraptorid eggshells (Figs. 3D-F). The deficiency of $\mathrm{P}$ in the surrounding sediments demonstrates that the distribution pattern of $\mathrm{P}$ in the studied eggshells is endogenous. Since ornithological research had suggested that $\mathrm{P}$ is an inhibitor of calcite growth during eggshell formation (Fink et al., 1993; Dennis et al., 1996; Fraser, Bain \& Solomon, 1999; Cusack, Fraser $\&$ Stachel, 2003), the similarity of P distribution between oviraptorid dinosaur and modern avian eggshells suggests that the oviraptorid dinosaurs studied by us already possessed a similar eggshell formation mechanism to that of extant birds.

Moreover, Cusack, Fraser \& Stachel (2003) also observed that the P concentration increases more sharply between the mammillary and prismatic layers in the eggshell of younger birds than in those of older birds. Therefore, the difference in P distribution between young and older birds can probably help paleontologists decipher whether an oviraptorid clutch was laid by a single female or by several females. If the whole clutch was produced by a single female or by several females of a similar age, all eggs should exhibit a similar pattern of $P$ concentration increase from the mammillary layer to the prismatic layer. Conversely, different patterns of increase would suggest that females of different ages contributed to a single clutch. Varricchio et al. (2008) compared the ratio of clutch mass to adult mass and proposed that an oviraptorid clutch was produced by several females. Yang et al. (2016) have provided preliminary supportive results based on statistical analyses of eggshell $\mathrm{P}$ distribution and external morphology in the same oviraptorid clutch.

On the other hand, in the Triprismatoolithus stephensi eggshell, P concentration varies slightly between the mammillary and prismatic layer but decreases significantly from the prismatic layer to the external layer (Fig. 4E). Such a pattern of P distribution differs from the one in oviraptorid or modern bird eggshells we discussed previously. Moreover, unlike a single peak of high $\mathrm{P}$ concentration in oviraptorid and modern eggshells, three distinctive peaks of high $\mathrm{P}$ concentration are present in the Triprismatoolithus stephensi eggshell. Based on the general deficiency of $\mathrm{P}$ in the 
365 surrounding sediment, we posit that the $\mathrm{P}$ peak in the sediment surrounding the

366 Triprismatoolithus stephensi eggshell is a result of a detached cuticle layer. The peak at

367 the boundary between the external layer and surrounding sediment represent the putative

368 cuticle layer (Fig. 4E). However, the peak at the boundary between the prismatic and

369 external layers was not reported previously in any avian eggshells (Fig. 4E). If the

370 sequestration of $\mathrm{P}$ is a crucial factor in the termination of calcite growth, the high

371

372

373

374

375

376

377

378

379

380

381

382

383 concentration of $\mathrm{P}$ on the boundary between the prismatic and external layers represents a possible temporal hiatus between the prismatic and external layers in the Triprismatoolithus eggshell.

\section{Interpretation of Raman spectra}

In the Raman study of the fossil eggshells, the peak at $967 \mathrm{~cm}^{-1}$ of Gallus eggshell was not seen in all spectra, but a broad peak ranging from $972-986 \mathrm{~cm}^{-1}$ was detected instead (Fig. 2A). The broad peak ranging from $972-986 \mathrm{~cm}^{-1}$ represent the phosphate groups, as indicated in Igic et al. (2015) (see also Supplemental Information). Three hypotheses can be formulated to explain the different spectral patterns from $960 \mathrm{~cm}^{-1}$ to $980 \mathrm{~cm}^{-1}$ in extant cuticle vs. the fossil eggshells.

First, theropod dinosaurs might have used whitlockite, a phosphate mineral containing hydrogen phosphate anions $\left(\mathrm{HPO}_{4}^{2-}\right)$, to form the inner cuticle layer instead of HAp. Whitlockite is the second most abundant mineral in biological calcified tissues, accounting for around $20 \%$ of bone mineral (Driessens \& Verbeeck, 1990; Jang et al., 2014; Jang et al., 2015). It is also possible that the HAp of the inner cuticle layer is in a non-stoichiometric form, and hence part of the phosphate anion $\left(\mathrm{PO}_{4}^{3-}\right)$ is occupied by hydrogen phosphate $\left(\mathrm{HPO}_{4}^{2-}\right)$ (Rey et al., 2011; De La Pierre et al., 2014).

Second, the original HAp of the inner cuticle layer could have been transformed to whitlockite. Jang et al. (2014) showed that HAp transforms into dicalcium phosphate dihydrate $\left(\mathrm{DCPD}, \mathrm{CaHPO}_{4} \cdot 2 \mathrm{H}_{2} \mathrm{O}\right.$ ) at $70{ }^{\circ} \mathrm{C}$. The DCPD is then converted into whitlockite $\left(\mathrm{Ca} 9(\mathrm{MgFe})\left(\mathrm{PO}_{4}\right)_{6} \mathrm{PO}_{3} \mathrm{OH}\right)$ by incorporating $\mathrm{Mg}^{2+}$ or $\mathrm{Fe}^{2+}$ when the $\mathrm{pH}$ decreases. In natural environments, such as the Nanxiong Formation and Two Medicine Formation, burial and diagenetic temperatures over $70^{\circ} \mathrm{C}$ are unlikely except by an intrusion of igneous origin. However, geological investigations did not provide any evidence for such igneous intrusions in the Nanxiong Basin (Erben, 1995). At the Sevenmile Hill outcrops in Montana, United States, Foreman et al. (2008) reported an altered volcanic ash layer (bentonite) that is depleted in P. However, the volcanic ash layer was deposited prior to the eggshells (Jackson \& Varricchio, 2010).

Third, the $\mathrm{P}$ we detected might be derived from the surrounding sediments during diagenesis. This is inconsistent with the preservation of pigments in the Nanxiong Basin eggshells and absence of igneous intrusions in both localities which suggests that the eggshells we studied experienced very little diagenesis (Erben, 1995; Foreman et al., 2008; Wiemann et al., 2017).

\section{Pigmentation on theropod eggshells}

As noted above, the discovery of protoporphyrin (Wiemann et al., 2017) in oviraptorid dinosaur eggshells from all three localities where the eggshells for this study were collected (Table 1) is consistent with the cuticle preservation. Although Wilson et al. (2017) indicated that pigment deposition and cuticle formation are not codependent, the preserved protoporphyrin pigments was probably from the cuticle layer. 
411

412

413

414

415

416

417

418

419

420

421

422

423

424

425

426

427

428

429

430

431

432

433

434

435

436

437

438

439

440

441

442

443

444

445

446

447

448

449

450

451

452

453

454

455

456

Thomas et al. (2015) performed Raman spectroscopy and mass spectrometry to show the detectability of pigments in extant avian eggshells. Our Raman analyses also demonstrate detectability of pigments in fossil eggshells; however, the peaks in the spectra do not completely correspondent with the ones shown in Thomas et al. (2015), suggesting further Raman studies using mass spectrometry on dinosaur eggshells.

\section{Nesting ecology of oviraptorid dinosaurs}

As noted, two nesting modes are recognized in birds, open and buried nesting (Varricchio \& Jackson, 2016). Most birds build open nests either on the tree or on the ground (ostriches or emus), while the megapode birds bury their eggs in a mound. Therefore, all open-nesting birds have eggshells of low porosity (Tanaka, Zelenitsky \& Therrien, 2015). However, an intermediate mode, semi-open nests in oviraptorid dinosaurs, was recently proposed based on detection of pigments and porosity evaluation (Yang et al., 2015; Wiemann et al., 2017). Pigmented eggshells strongly suggest an open nesting mode. However, the porosity evaluation revealed a heterogeneous distribution of porosity-highest porosity in the lower middle part (buried) and lowest porosity in the blunt end (open) (Yang et al., 2015; Wiemann et al., 2017), thus indicating a semi-open nesting mode. This intermediate mode is consistent with the fluvial environment inferred by sedimentological investigations in the Nanxiong Basin (Erben, 1995). In such a humid fluvial environment, the risk of microbial invasions was much higher. The cuticular nanospheres, which are associated with humid environments and protect extant eggs from microbial invasions, were likely present in the oviraptorid and alvarezsaurid dinosaur eggs from these fossil humid environments as well. Although we did not detect cuticular nanospheres in the dinosaur eggshell, our detection of a cuticle layer suggests it to have been an adaptation the oviraptorid and alvarezsaurid dinosaurs nesting in a humid fluvial environment (D'Alba et al., 2016).

On the other hand, it was inferred that Mongolian oviraptorid clutches were deposited in a xeric environment. The evidence is the eolian nature (sand dune deposits) in the Baruungoyot and the Djadokhta formations (Norell et al., 1995). Although no Mongolian oviraptorid eggshells were included in our study, it appears likely that Mongolian oviraptorid eggs were also cuticlecoated for the prevention of water loss as in Adélie penguin eggs (Thompson \& Goldie, 1990). Fanti, Currie \& Demchig (2012) documented clutches of the oviraptorid Nemegtomaia from both the Nemegt and Baruungoyot formations, that represent mesic and xeric habitats, respectively. Moreover, they also provided evidence for the lateral coexistence of mesic and xeric habitats in the Baruungoyot Formation and posited that Nemegtomaia and other Mongolian oviraptorid dinosaurs nested near permanent or seasonal streams. In such a variable environment, the cuticlecoated eggs, therefore, would have been an adaptive trait that enhanced reproductive success of oviraptorid dinosaurs.

While it is uncertain that the alvarezsaurid eggshells were pigmented without further chemical studies, it is possible that alvarezsaurid dinosaur exploited similar nesting strategies as oviraptorid dinosaurs did.

\section{Taphonomic implications for cuticle preservation}

The cuticle layer is a labile, easily lost structure that appears unlikely to be preserved during the fossilization process. Our study thus raises an important taphonomic question, i.e., how did the cuticle layer get preserved? Since the cuticle preservation observed by us appears to pertain to eggshell from clutches and not from dispersed eggshell, cuticle preservation probably is 
457 facilitated by fossilization of eggs in clutches. Furthermore, a layer of secondary diagenetic

458 calcite is commonly observed on eggshells from fluvial deposits (Fig. 3A; Jackson et al., 2010).

459 This layer of secondary calcite may have been a rigid shield that protected the cuticle layer from

460 mechanical removal.

461

462

463

464

465

466

467

468

469

470

471

472

473

474

475

476

477

478

479

480

481

482

483

484

485

486

487

488

489

490

491

492

493

494

495

496

497

498

499

\section{Acknowledgements}

The SEM observations and EPMA analyses were performed at the Steinmann-Institute of the University of Bonn, Bonn, Germany. Prof. Dr. Andreas Erbe and Ms. Petra Ebbinghaus kindly provided the access to the WItec Raman and Horiba Jobin Yvon Raman spectrometers at the MPIE. Fossil eggshell samples were provided by Prof. David Varricchio at the Montana State University, Dr. Georg Heumann at the STIPB, and Prof. Dr. Yen-Nien Cheng at the NMNS. This is contribution number 1 of DFG Research Unit 2685 "The Limits of the Fossil

Record: Analytical and Experimental Approaches to Fossilization. “ 


\section{References}

501 Agnolin FL, Powell JE, Novas FE, Kundrát M. 2012. New alvarezsaurid (Dinosauria, Theropoda) from uppermost Cretaceous of north-western Patagonia with associated eggs. Cretaceous Research 35:33-56. DOI: 10.1016/j.cretres.2011.11.014

Ahmed TAE, Suso H-P, Hincke MT. 2017. In-depth comparative analysis of the chicken eggshell membrane proteome. Journal of Proteomics 155:49-62. DOI: 10.1016/j.jprot.2017.01.002

Board RG. 1982. Properties of avian egg shells and their adaptive value. Biological Reviews 57:1-28. DOI:10.1111/j.1469-185X.1982.tb00362.x

Board RG, Fuller R. 1974. Non-specific antimicrobial defences of the avian egg, embryo, and neonate. Biological Reviews 49:15-49. DOI: 10.1111/j.1469-185X.1974.tb01297.x

Board RG, Halls NA. 1973. The cuticle: A barrier to liquid and particle penetration of the shell of the hen's egg. British Poultry Science 14:69-97. DOI: 10.1080/00071667308415999

Chen L, Steel, RJ, Guo F, Olariu C, Gong C. 2017. Alluvial fan facies of the Yongchong Basin: Implications for tectonic and paleoclimatic changes during Late Cretaceous in SE China. Journal of Asian Earth Sciences 134:37-54. DOI: 10.1016/j.jseaes.2016.10.010

Cheng Y-N, Ji C, Wu X, Shan H-Y. 2008. Oviraptorosaurian eggs (Dinosauria) with embryonic skeletons discovered for the first time in China. Acta Geologica Sinica 82:1089-1094. DOI: $10.1111 /$ j.1755-6724.2008.tb00708.x

Chow M. 1954. Additional notes on the microstructure of the supposed dinosaurian eggshells from Laiyang, Shantung. Acta Palaeontologica Sinica 2:389-394.

Crane NJ, Popescu V, Morris MD, Steenhuis P, Ignelzi MA. 2006. Raman spectroscopic evidence for octacalcium phosphate and other transient mineral species deposited during intramembranous mineralization. Bone 39:434-442. DOI: 10.1016/j.bone.2006.02.059

Cusack M, Fraser AC, Stachel T. 2003. Magnesium and phosphorus distribution in the avian eggshell. Comparative Biochemistry and Physiology Part B: Biochemistry and Molecular Biology 134:63-69. DOI: 10.1016/S1096-4959(02)00185-9

D’Alba L, Jones DN, Badawy HT, Eliason CM, Shawkey, MD. 2014. Antimicrobial effects of a nanostructured eggshell in a compost-nesting bird. Journal of Experimental Biology 217: 1116-1121. DOI: 10.1111/ibi.12527

D’Alba L, Maia R, Hauber ME, Shawkey MD. 2016. The evolution of eggshell cuticle in relation to nesting ecology. Proceedings of the Royal Society B: Biological Sciences 283. DOI: $10.1098 / \mathrm{rspb} .2016 .0687$

D'Alba L, Torres R, Waterhouse GIN, Eliason C, Hauber ME, Shawkey MD. 2017. What does the eggshell cuticle do? A functional comparison of avian eggshell cuticles. Physiological and Biochemical Zoology 90:588-599. DOI:10.1086/693434

De La Pierre M, Carteret C, Maschio L, André E, Orlando R, Dovesi R. 2014. The Raman spectrum of $\mathrm{CaCO}_{3}$ polymorphs calcite and aragonite: a combined experimental and computational study. The Journal of chemical physics 140:164509. DOI: $10.1063 / 1.4871900$

Deeming DC. 1987. Effect of cuticle removal on the water vapour conductance of egg shells of several species of domestic bird. British Poultry Science 28:231-237. DOI: $10.1080 / 00071668708416957$

Deeming DC. 2006. Ultrastructural and functional morphology of eggshells supports the idea that dinosaur eggs were incubated buried in a substrate. Palaeontology 49:171-185. DOI: 10.1111/j.1475-4983.2005.00536.x 
546

547

548

549

550

551

552

553

554

555

556

557

558

559

560

561

562

563

564

565

566

567

568

569

570

571

572

573

574

575

576

577

578

579

580

581

582

583

584

585

586

587

588

589

590

591

Dennis JE, Xiao SQ, Agarwal M, Fink DJ, Heuer AH, Caplan AI. 1996. Microstructure of matrix and mineral components of eggshells from White Leghorn chickens (Gallus gallus). Journal of Morphology 228:287-306.

Driessens FCM, Verbeeck RK. 1990. Biominerals. Boca Raton, FL: CRC Press.

Erben HK. 1995 (ed.). Die Kreide/Tertiär-Grenze im Nanxiong-Becken: Kontinentalfazies, Südostchina. Stuttgart: Franz Steiner Verlag GmbH.

Fanti F, Currie PJ, Demchig B. 2012. New Specimens of Nemegtomaia from the Baruungoyot and Nemegt Formations (Late Cretaceous) of Mongolia. PLoS One 7: e31330. DOI: 10.1371/journal.pone.0031330

Fecheyr-Lippens DC, Igic B, D’Alba L, Hanley D, Verdes A, Holford M, Waterhouse GIN, Grim T, Hauber ME, Shawkey MD. 2015. The cuticle modulates ultraviolet reflectance of avian eggshells. Biology Open 4:753-759. DOI: 10.1242/bio.012211

Ferguson MWJ. 1982. The structure and composition of the eggshell and embryonic membranes of Alligator mississippiensis. The Transactions of the Zoological Society of London 36:99-152. DOI: 10.1111/j.1096-3642.1982.tb00064.x

Fink DJ, Kuhn LT, Caplan AI, Huer AH. 1993. Eggshell assembly, a model for biomimetic ceramic production. In: Nys Y, ed. Fifth European Symposium on the Quality of Egg and Egg Products. Tours: WPSA. p. A1-A6.

Foreman BZ, Rogers RR, Deino AL, Wirth KR, Thole JT. 2008. Geochemical characterization of bentonite beds in the Two Medicine Formation (Campanian, Montana), including a new ${ }^{40} \mathrm{Ar} /{ }^{39} \mathrm{Ar}$ age. Cretaceous Research 29:373-385. DOI: 10.1016/j.cretres.2007.07.001

Fraser AC, Bain MM, Solomon SE. 1999. Transmission electron microscopy of the vertical crystal layer and cuticle of the eggshell of the domestic fowl. British Poultry Science 40:626-631. DOI: 10.1080/00071669987016

Frost RL, Scholz R, López A, Xi Y. 2014. A vibrational spectroscopic study of the phosphate mineral whiteite $\mathrm{CaMn}^{++} \mathrm{Mg}_{2} \mathrm{Al}_{2}\left(\mathrm{PO}_{4}\right)_{4}(\mathrm{OH})_{2} \cdot 8\left(\mathrm{H}_{2} \mathrm{O}\right)$. Spectrochimica Acta Part A: Molecular and Biomolecular Spectroscopy 124:243-248. DOI: 10.1016/j.saa.2014.01.053

Gergely G, Wéber F, Lukács I, Tóth AL, Horváth ZE, Mihály J, Balázsi C. 2010. Preparation and characterization of hydroxyapatite from eggshell. Ceramics International 36:803806. DOI: 10.1016/j.ceramint.2009.09.020

Grellet-Tinner G. 2005. Membrana testacea of titanosaurid dinosaur eggs from Auca Mahuevo (Argentina): Implications for exceptional preservation of soft tissue in Lagerstätten. Journal of Vertebrate Paleontology 25:99-106. DOI: 10.1671/02724634(2005)025[0099:mtotde]2.0.co;2

Grellet-Tinner G, Fiorelli LE. 2010. A new Argentinean nesting site showing neosauropod dinosaur reproduction in a Cretaceous hydrothermal environment. Nature Communications 1:32. DOI: 10.1038/ncomms1031

Hanson BA. 2017. ChemoSpec: Exploratory Chemometrics for Spectroscopy, $R$ package version 4.4.97.

He F, Huang X, Li X. 2017. Occurrence rule and buried characteristics of dinosaur fossils in the Ganzhou Basin, Jiangxi Province. East China Geology 38:250-254. DOI:10.16788/j.hddz.32-1865/P.2017.04.002

Hechenleitner EM, Grellet-Tinner G, and Fiorelli LE. 2015. What do giant titanosaur dinosaurs and modern Australasian megapodes have in common? PeerJ 3:e1341. DOI: $10.7717 /$ peerj.1341

Igic B, Fecheyr-Lippens D, Xiao M, Chan A, Hanley D, Brennan PRL, Grim T, Waterhouse 
592

593

594

595

596

597

598

599

600

601

602

603

604

605

606

607

608

609

610

611

612

613

614

615

616

617

618

619

620

621

622

623

624

625

626

627

628

629

630

631

632

633

634

635

636

637
GIN, Hauber ME, Shawkey MD. 2015. A nanostructural basis for gloss of avian eggshells. Journal of The Royal Society Interface 12:20141210. DOI:

10.1098/rsif.2014.1210

Jackson FD. 2007. Titanosaur reproductive biology: comparison of the Auca Mahuevo titanosaur nesting locality (Argentina), to the Pinyes Megaloolithus nesting locality (Spain). Ph.D. Thesis, Montana State University.

Jackson FD, Varricchio DJ. 2010. Fossil eggs and eggshell from the lowermost Two Medicine Formation of western Montana, Sevenmile Hill locality. Journal of Vertebrate Paleontology 30:1142-1156. DOI: 10.1080/02724634.2010.483537

Jang HL, Jin K, Lee J, Kim Y, Nahm SH, Hong KS, Nam KT. 2014. Revisiting whitlockite, the second most abundant biomineral in bone: nanocrystal synthesis in physiologically relevant conditions and biocompatibility evaluation. ACS Nano 8:634-641. DOI: $10.1021 / \mathrm{nn} 405246 \mathrm{~h}$

Jang HL, Lee HK, Jin K, Ahn H-Y, Lee H-E, Nam KT. 2015. Phase transformation from hydroxyapatite to the secondary bone mineral, whitlockite. Journal of Materials Chemistry B 3:1342-1349. DOI: 10.1039/c4tb01793e

Kennedy GY, Vevers HG. 1976. A survey of avian eggshell pigments. Comparative Biochemistry and Physiology Part B: Comparative Biochemistry 55:117-123. DOI: 10.1016/0305-0491(76)90183-8

Kohring R, Hirsch KF. 1996. Crocodilian and avian eggshells from the Middle Eocene of the Geiseltal, Eastern Germany. Journal of Vertebrate Paleontology 16:67-80. DOI: 10.1080/02724634.1996.10011285

Kusada S, Iwasawa A, Doi O, Ohya Y, Yoshizaki N. 2011. Diversity of the cuticle layer of avian eggshells. Journal of Poultry Science 48:119-124. DOI: 10.2141/jpsa.010103.

Maiber M, Reglin B, Nitzsche B, Xiang W, Rong WW, Hoffmann B, Djonov V, Secomb TW, Pries AR. 2016. Structure and hemodynamics of vascular networks in the chorioallantoic membrane of the chicken. American Journal of Physiology 311:913-926. DOI: 10.1152/ajpheart.00786.2015

Mikhailov KE. 1991. Classification of fossil eggshells of amniotic vertebrates. Acta Palaeontologica Polonica 36.

Mikhailov KE, Ornithologists' Club B. 1997. Avian Eggshells: An Atlas of Scanning Electron Micrographs. Tring: British Ornithologists' Club.

Mikšík I, Eckhardt A, Sedláková P, Mikulikova K. 2007. Proteins of insoluble matrix of avian (Gallus gallus) eggshell. Connective Tissue Research 48:1-8. DOI: 10.1080/03008200601003116

Norell MA, Clark JM, Chiappe LM, Dashzeveg D. 1995. A nesting dinosaur. Nature 378:774776. DOI: $10.1038 / 378774 \mathrm{a} 0$

Nys Y, and Guyot N. 2011. Egg formation and chemistry. In: Nys Y, Bain M, and van Immerseel F, eds. Improving the Safety and Quality of Eggs and Egg Products. Cambridge: Woodhead Publishing, p. 83-132.

Nys Y, Zawadzki J, Gautron J, Mills A. 1991. Whitening of brown-shelled eggs: mineral composition of uterine fluid and rate of protoporphyrin deposition. Poultry Science 70:1236-1245.

Oskam CL, Haile J, McLay E, Rigby P, Allentoft ME, Olsen ME, Bengtsson C, Miller GH, Schwenninger J-L, Jacomb C, Walter R, Baynes A, Dortch J, Parker-Pearson M, Gilbert MTP, Holdaway RN, Willerslev E, Bunce M. 2010. Fossil avian eggshell preserves 
638

639

640

641

642

643

644

645

646

647

648

649

650

651

652

653

654

655

656

657

658

659

660

661

662

663

664

665

666

667

668

669

670

671

672

673

674

675

676

677

678

679

680

681

682

683 ancient DNA. Proceedings of the Royal Society of London B: Biological Sciences 277:1991-2000. DOI: 10.1098/rspb.2009.2019

Packard MJ, DeMarco VG. 1991. Eggshell structure and formation in eggs of oviparous reptiles. In: Deeming, CD, Ferguson MWJ, eds. Egg Incubation: Its Effects on Embryonic Development in Birds and Reptiles. Cambridge: Cambridge University Press.

Rahman MA, Moriyama A, Iwasawa A, Yoshizaki N. 2009. Cuticle formation in quail eggs. Zoological Science 26:496-499. DOI: 10.2108/zsj.26.496

Reisz RR, Huang TD, Roberts EM, Peng S, Sullivan C, Stein K, LeBlanc ARH, Shieh D, Chang R, Chiang C, Yang C, Zhong S. 2013. Embryology of Early Jurassic dinosaur from China with evidence of preserved organic remains. Nature 496:210-214. DOI: 10.1038/nature11978

Rey C, Combes C, Drouet C, Grossin D. 2011. Bioactive ceramics: Physical chemistry. In: Ducheyne P, Healy K, Hutmacher D, Grainger DE, Kirkpatrick J, eds. Comprehensive Biomaterials. Oxford: Elsevier, p. 187-221.

Rodríguez-Navarro AB, Domínguez-Gasca N, Muñoz A, Ortega-Huertas M. 2013. Change in the chicken eggshell cuticle with hen age and egg freshness. Poultry Science 92:3026-3035. DOI: $10.3382 /$ ps.2013-03230

Romanoff AL, Romanoff AJ. 1949. The Avian Egg. Hoboken, NJ: John Wiley \& Sons Inc.

Sander PM, Peitz C, Gallemi J, Cousin R. 1998. Dinosaur nesting on a red beach? Comptes Rendus de l'Académie des Sciences 327:67-74.

Sander PM, Peitz C, Jackson FD, Chiappe LM. 2008. Upper Cretaceous titanosaur nesting sites and their implications for sauropod dinosaur reproductive biology. Palaeontographica Abteilung A:69-107.

Sauer GR, Zunic WB, Durig JR, Wuthier RE. 1994. Fourier transform Raman spectroscopy of synthetic and biological calcium phosphates. Calcified Tissue International 54:414-420. DOI: $10.1007 / \mathrm{bf00305529}$

Schwartz S, Stephenson BD, Sarkar DH, Bracho MR. 1975. Red, white, and blue eggs as models of porphyrin and heme metabolism. Annals of the New York Academy of Sciences 244:570-588.

Schweitzer MH, Wittmeyer JL, Horner JR, Toporski JK. 2005. Soft-tissue vessels and cellular preservation in Tyrannosaurus rex. Science 307:1952-1955. DOI:10.1126/science.1108397

Simons PCM. 1971. Ultrastructure of hen's egg physiological interpretation. Ph.D. Dissertation, Agricultural University.

Sochava AV. 1971. Two types of egg shells of Senonian dinosaurs. Paleontologicheskii Zhurnal 3:80-88.

Tanaka K, Zelenitsky DK, Therrien F. 2015. Eggshell porosity provides insight on evolution of nesting in dinosaurs. PLoS ONE 10:e0142829. DOI: 10.1371/journal.pone.0142829

Thomas DB, Hauber ME, Hanley D, Waterhouse GIN, Fraser S, Gordon KC. 2015. Analysing avian eggshell pigments with Raman spectroscopy. The Journal of Experimental Biology 218:2670-2674. DOI: 10.1242/jeb.124917

Thompson MB, Goldie KN. 1990. Conductance and structure of eggs of Adelie penguins, Pygoscelis adeliae, and its implications for incubation. The Condor 92:304-312. DOI:10.2307/1368228

Varricchio DJ, Jackson F, Borkowski JJ, Horner JR. 1997. Nest and egg clutches of the dinosaur Troodon formosus and the evolution of avian reproductive traits. Nature 385:247-250. 
684

685

686

687

688

689

690

691

692

693

694

695

696

697

698

699

700

701

702

703

704

705

706

707

708

709

710

711

712

713

714

715

716

717

718

719

720

721

722

723

724

Varricchio DJ, Jackson FD. 2004. A phylogenetic assessment of prismatic dinosaur eggs from the Cretaceous Two Medicine Formation of Montana. Journal of Vertebrate Paleontology 24:931-937. DOI: 10.1671/0272-4634(2004)024[0931:apaopd]2.0.co;2

Varricchio DJ, Jackson FD. 2016. Reproduction in Mesozoic birds and evolution of the modern avian reproductive mode. The Auk 133:654-684. DOI: 10.1642/auk-15-216.1

Varricchio DJ, Jackson FD, Jackson RA, Zelenitsky DK. 2013. Porosity and water vapor conductance of two Troodon formosus eggs: an assessment of incubation strategy in a maniraptoran dinosaur. Paleobiology 39:278-296. DOI: 10.1666/11042

Varricchio DJ, Moore JR, Erickson GM, Norell MA, Jackson FD, Borkowski JJ. 2008. Avian paternal care had dinosaur origin. Science 322:1826-1828. DOI: 10.1126/science. 1163245

Vila B, Jackson FD, Fortuny J, Sellés AG, Galobart À. 2010. 3-D modelling of megaloolithid clutches: Insights about nest construction and dinosaur behaviour. PLoS ONE 5:e10362. DOI: 10.1371/journal.pone.0010362

Walters MA, Leung YC, Blumenthal NC, Konsker KA, LeGeros RZ. 1990. A Raman and infrared spectroscopic investigation of biological hydroxyapatite. Journal of Inorganic Biochemistry 39:193-200. DOI: 10.1016/0162-0134(90)84002-7

Wedral EM, Vadehra DV, Baker RC. 1974. Chemical composition of the cuticle, and the inner and outer shell membranes from eggs of Gallus gallus. Comparative Biochemistry and Physiology Part B: Comparative Biochemistry 47:631-640. DOI: 10.1016/03050491(74)90011-X

Wiemann J, Yang T-R, Sander PN, Schneider M, Engeser M, Kath-Schorr S, Müller CE, Sander PM. 2017. Dinosaur origin of egg color: oviraptors laid blue-green eggs. PeerJ 5:e1323. DOI: $10.7717 /$ peerj.3706

Wilson PW, Suther CS, Bain MM, Icken W, Jones A, Quinlan-Pluck F, Olori V, Gautron J, Dunn IC. 2017. Understanding avian egg cuticle formation in the oviduct: a study of its origin and deposition. Biology of Reproduction 97:39-49. DOI:10.1093/biolre/iox070

Yang T-R, Sander PM, Wiemann J, Cheng Y-N. 2015. Reproductive biology of the oviraptorid dinosaurs revealed by the interpreted egg inner structures. In: Canoville P, Mitchel J, Stein K, Konietzko-Meier D, Teschner E, van Heteren A, Sander PM, eds. Program and Abstracts Book of the Third International Symposium of Paleohistology. Bonn, Germany. p. 33.

Yang T-R, van Heteren A, Wiemann J, Chen C-J, Spiering B. 2016. Communal nesting behavior of dinosaurs revealed by statistical analyses of phosphorus distribution in, and external morphology of, eggshells. In: Farke A, MacKenzie A, Miller-Camp J, eds. Program and Abstracts Book of the 76th SVP Annual Meeting. Salt Lake City, Utah, United States: Society of Vertebrate Paleontology. p. 255.

Zhang S. 2009. Hugang Formation. In: Zhang S, ed. Geological Formation Names of China (1866-2000). Berlin: Springer Verlag, p. 466.

Zhao, Z. 1975. Microstructures of the dinosaurian eggshells of Nanxiong, Guangdong, and the problems in egg classification. Vertebrata Palasiatica 13(2):105-117. 


\section{Figure 1}

Cross-sectional view, SEM images, and Raman imaging and spectrum of a Gallus gallus domesticus egg and eggshell.

The Raman image and spectrum were collected using $532 \mathrm{~nm}$ excitation wavelength and a 50x objective with RI. (A) The generalized anatomy of an egg. (B) The chicken eggshell comprises three crystalline layers, including the mammillary layer, prismatic layer, and external layer. The cuticle layer overlying the calcareous eggshell is further divided to two layers, including a HAp inner layer and a proteinaceous outer layer. The shell membrane, namely membrane testacea, is also characterized by two layers. (C) SEM image of the cuticle on the surface of the Gallus eggshell, showing a patchy and cracking pattern. (D) SEM image of the radial section of the Gallus eggshell. The white arrow indicates the cuticle layer that lies on the calcitic eggshell. (E) Raman chemical image with peak targeting at $967 \mathrm{~cm}^{-1}$ which is attributed to HAp. The yellow area represents the patchy distribution of the inner HAp cuticle layer on the Gallus eggshell. The calcitic eggshell that is not covered by the inner HAp cuticle layer is shown in the brown area. The dotted circle corresponds to the spectrum shown in (F). (F) Spectrum collected in the dotted-circle area of the Raman chemical image shown in (E). Two significant peaks at $967 \mathrm{~cm}^{-1}$ and $1087 \mathrm{~cm}^{-1}$ represent HAp and calcite, respectively. Credit of the SEM images and drawings: Tzu-Ruei Yang (Universität Bonn). 

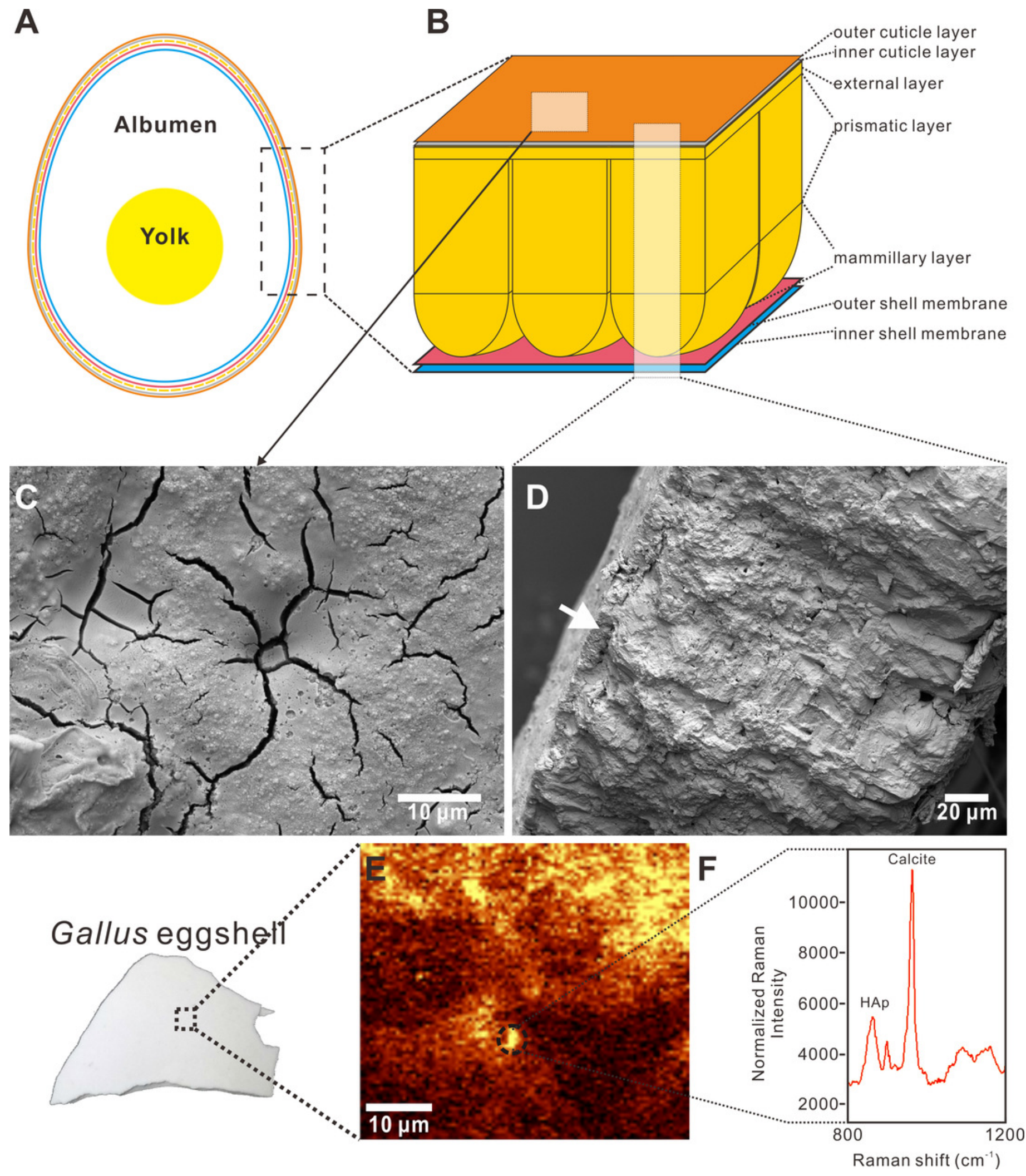
Figure 2

Raman spectra and chemometric analysis.

(A) Raman spectra derived from chicken, crocodilian, fossil dinosaur eggshells, and surrounding sediments. The peaks around $972-986 \mathrm{~cm}^{-1}$ and $1063-1097 \mathrm{~cm}^{-1}$ are marked by yellow bars, indicating the calcite and phosphate bonds. (B) The principle component chemometric analysis on the spectral area of $800-1200 \mathrm{~cm}^{-1}$ shown in $(A)$ demonstrates significant disparities between dinosaur/chicken eggshells, crocodilian eggshells, and sediments. Credit of the drawings: Tzu-Ruei Yang (Universität Bonn).
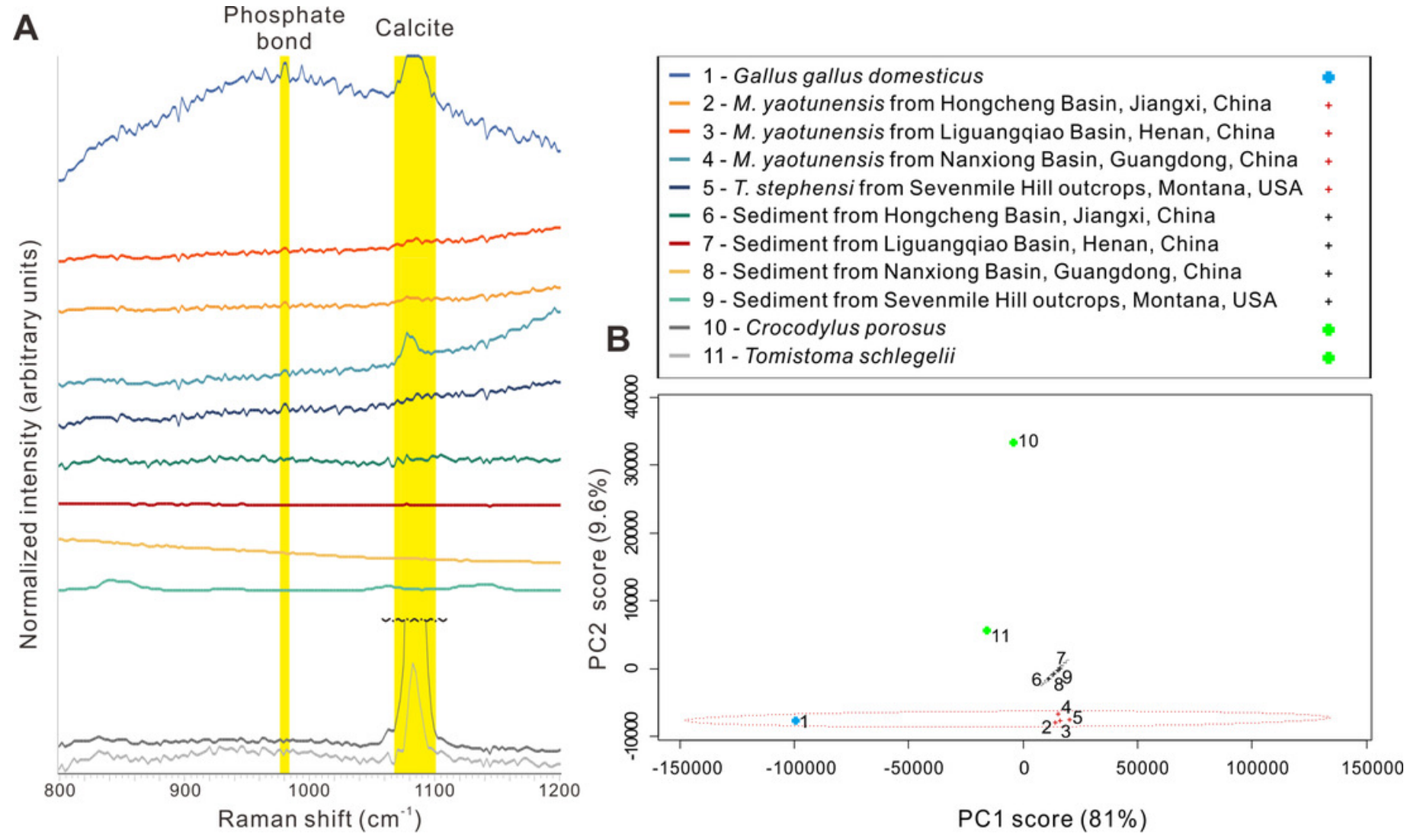


\section{Figure 3}

Microscopic images of Macroolithus yaotunensis eggshell from Henan, Jiangxi, and Guangdong and their line-scan spectra.

(A) The Macroolithus yaotunensis eggshell (NMNS CYN-2004-DINO-05-I) from Jiangxi under the polarized light microscope. The red arrows indicate the indistinct boundary between the sediment and an enigmatic layer. This enigmatic layer probably was formed by the interaction between organics of the egg and surrounding sediment. The location of the EPMA line-scan spectra in (D) is indicated by the white solid line. In this eggshell image, a smooth boundary between the prismatic and mammillary layers (PL and ML, seen as dark and light zones) is clearly observed. (B) SEM image of radial untreated fracture of the Macroolithus yaotunensis eggshell. The boundary between the sediment and prismatic layer is marked by yellow dashed line based on their distinct structural features. The boundary between ML and $\mathrm{PL}$ is marked by the red dashed line. The ML shows the distinct vertical mammillae structure. (C) Close-up image of the area in white box in (B). Possible preservation of cuticle is indicated by the white arrow, showing patchy and flaky structures similar to the cuticle on the modern chicken eggshell (Figs. 1C\& 1D). (D)-(F) The microscopic image to the left of the spectra shows the radial cut section of studied Macroolithus yaotunensis eggshells seen in the SEM coupled with the EPMA and elemental line-scan track marked as black lines. (D) The spectra illustrate the distribution of $\mathrm{Ca}$ and $\mathrm{P}$ across the eggshell from the Hongcheng Basin in Jiangxi shown in (A), from innermost (left) to outermost, as indicated by the white line in the microscopic image. The Ca spectrum clearly marks the extent of the calcitic eggshell. A significant peak that is marked by a black arrow demonstrates a relatively high concentration of $\mathrm{P}$, indicating the possible preservation of the cuticular HAp layer. (E) The spectra illustrate the distribution of $\mathrm{Ca}$ and $\mathrm{P}$ across the eggshell from the Liguangqiao Basin in Henan, from innermost (left) to outermost. The Ca spectrum clearly marks the extent of the calcitic eggshell. A slightly higher amount of $\mathrm{P}$ near the interface between the eggshell and 
sediments, as indicated by a black arrow, is observed. (F) The spectra illustrate the distribution of $\mathrm{Ca}$ and $\mathrm{P}$ across the eggshell from the Nanxiong Basin in Guangdong, from innermost (left) to outermost. A significant peak that is marked by a black arrow demonstrates a relatively high concentration of $P$, indicating the possible preservation of the cuticular HAp layer. ML, mammillary layer; PL, prismatic layer. Credit of the SEM images and drawings: Tzu-Ruei Yang (Universität Bonn). 

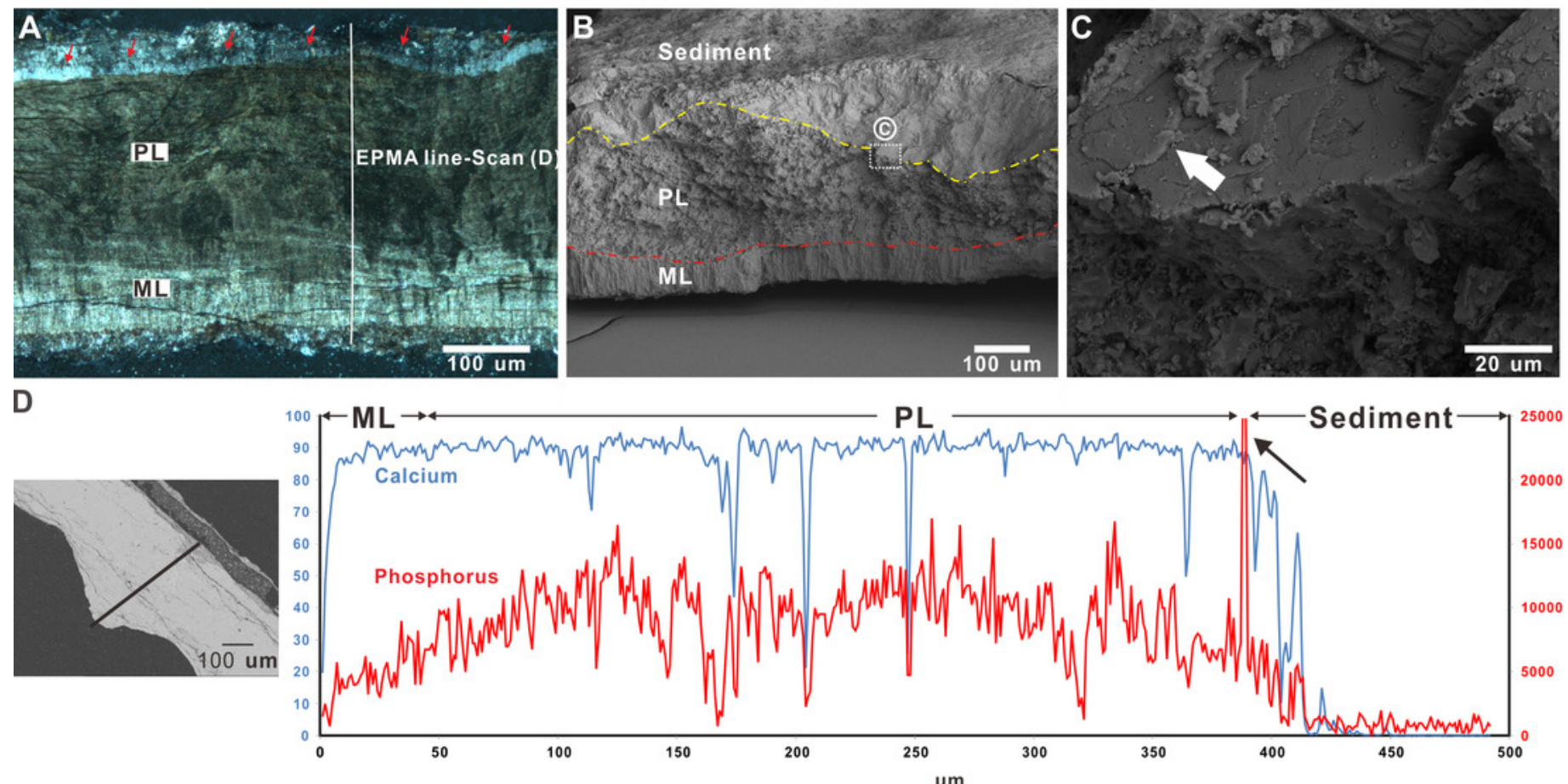

E
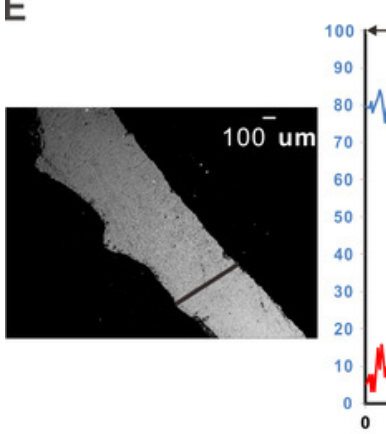

ML

PL

Sediment

$\longrightarrow$

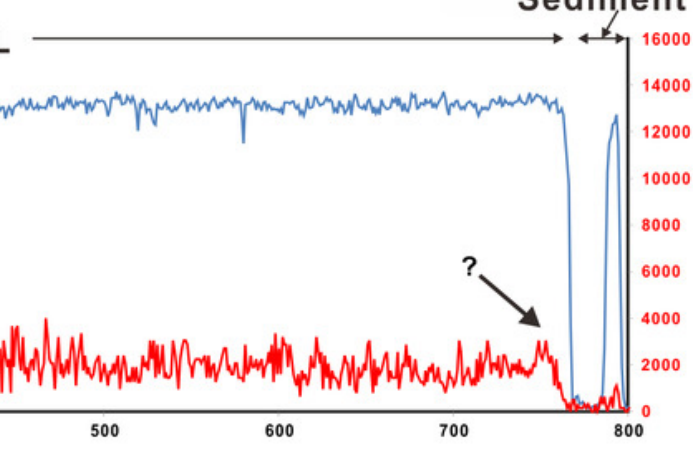

F

moraspane calcium mannm monuerypromery 


\section{Figure 4}

SEM images of the Triprismatoolithus eggshell and EPMA line-scan spectra.

(A) The radial cut section of studied Triprismatoolithus eggshell in the SEM coupled with the EPMA. (B) The probable flake-like cuticle structure atop the eggshell, marked by the white arrow. The red dotted line marks the outermost boundary of the prismatic layer. (C) An enigmatic structure (white arrow) protruding from the mammillary layer, possibly a fiber of the membrana testacea extending into the mammillary layer. (D) Enlargement of the possible fiber. (E) Line scans across eggshell in (A). The scan shows a high concentration of $P$ at the boundary between the eggshell and surrounding sediment. Two other peaks of P were observed on the boundary between the external and prismatic layer and in the sediment. The $P$ concentration does not differ between the mammillary and prismatic layers; however, the external layer showed a significantly lower concentration of $\mathrm{P}$ than the mammillary and prismatic layers. EL, external layer; $\mathrm{ML}$, mammillary layer; PL, prismatic layer. Credit of the SEM images and drawings: Tzu-Ruei Yang (Universität Bonn). 

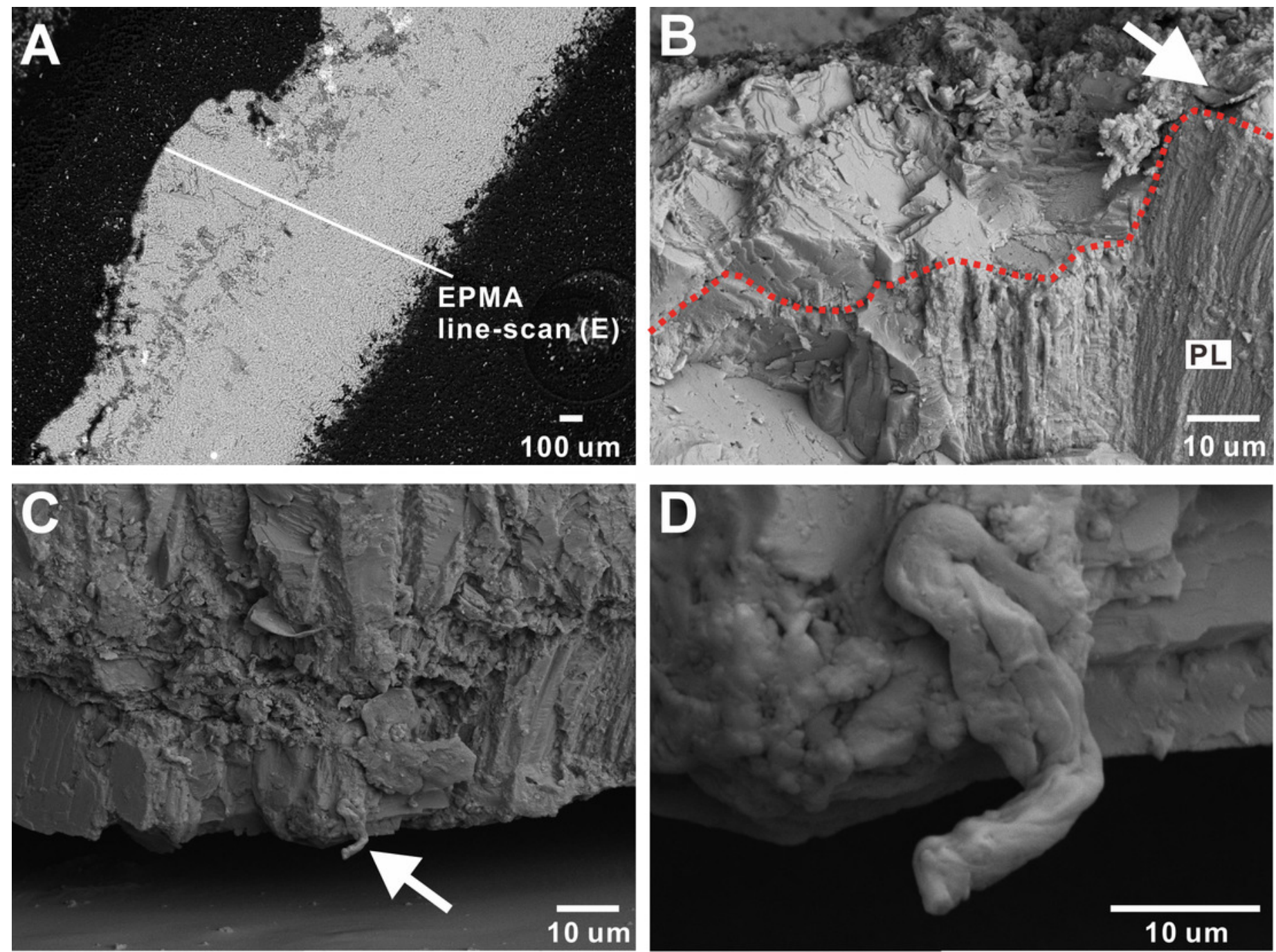

E

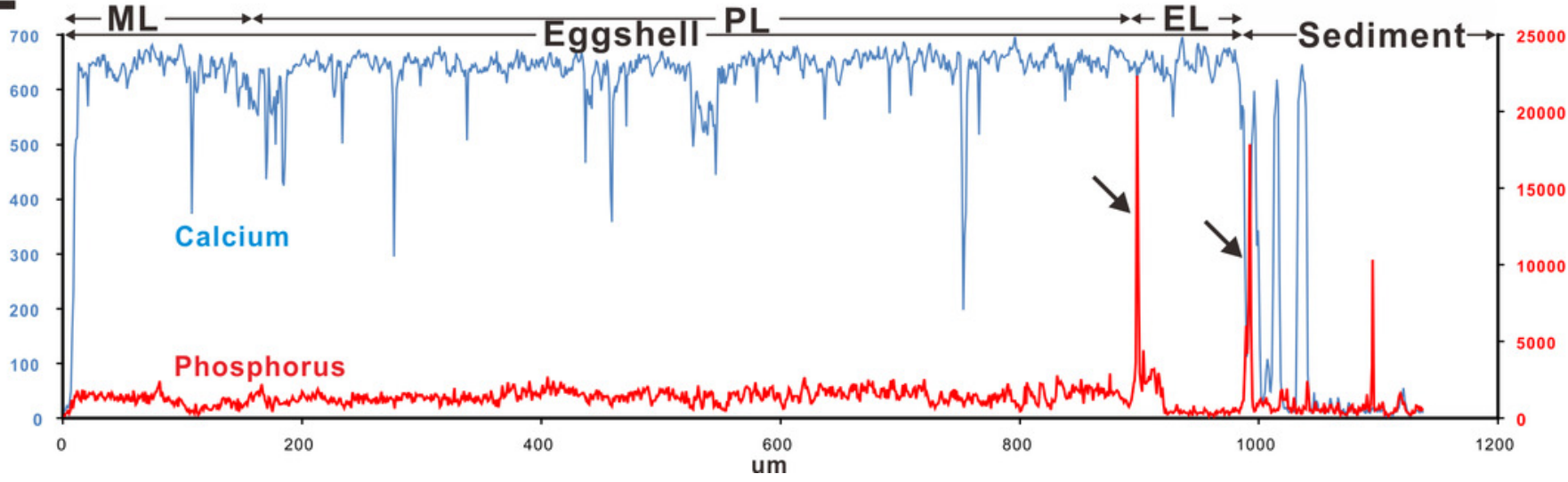




\section{Table $\mathbf{1}$ (on next page)}

Eggshells analyzed in this study

The ootaxonomic/taxonomic assignments, stratigraphic and locality information, and catalog numbers of the eggshells analyzed in this study 


\section{Tables}

2 Table 1 Eggshells analyzed in this study.

\begin{tabular}{|c|c|c|c|c|}
\hline $\begin{array}{l}\text { Oospecies or } \\
\text { species }\end{array}$ & Stratigraphy & Locality & Catalog number & Reference \\
\hline $\begin{array}{l}\text { Macroolithus } \\
\text { yaotunensis }\end{array}$ & Tangbian Formation & $\begin{array}{l}\text { Hongcheng Basin, Jiangxi } \\
\text { Province, China }\end{array}$ & $\begin{array}{l}\text { NMNS CYN-2004- } \\
\text { DINO-05-I }\end{array}$ & $\begin{array}{l}\text { Wiemann et al. } \\
2017\end{array}$ \\
\hline $\begin{array}{l}\text { Macroolithus } \\
\text { yaotunensis }\end{array}$ & Hugang Formation & $\begin{array}{l}\text { Liquanqiao Basin, Henan } \\
\text { Province, China }\end{array}$ & STIPB-E131 & $\begin{array}{l}\text { Wiemann et al. } \\
2017\end{array}$ \\
\hline $\begin{array}{l}\text { Macroolithus } \\
\text { yaotunensis }\end{array}$ & Pingling Formation & $\begin{array}{l}\text { Nanxiong Basin, } \\
\text { Guangdong Province, China }\end{array}$ & STIPB-E66 & $\begin{array}{l}\text { Wiemann et al. } \\
2017\end{array}$ \\
\hline $\begin{array}{l}\text { Triprismatoolithus } \\
\text { stephensi }\end{array}$ & $\begin{array}{l}\text { Lower portion of the } \\
\text { Upper Cretaceous } \\
\text { (Campanian) Two } \\
\text { Medicine Formation }\end{array}$ & $\begin{array}{l}\text { Dave and Joel Site, } \\
\text { Sevenmile Hill outcrops, } \\
\text { Teton County, Montana }\end{array}$ & MOR ES101 & $\begin{array}{l}\text { Jackson and } \\
\text { Varricchio } 2010\end{array}$ \\
\hline Gallus gallus & - & Bonn, Germany & - & - \\
\hline Crocodylus porosus & - & Taichung, Taiwan & $\begin{array}{l}\text { uncatalogued } \\
\text { specimen in NMNS }\end{array}$ & - \\
\hline Tomistoma schlegelii & - & Taichung, Taiwan & $\begin{array}{l}\text { uncatalogued } \\
\text { specimen in NMNS }\end{array}$ & - \\
\hline
\end{tabular}

3 